\title{
Anatomy and Neurocontrol of the Pelvic Floor
}

\author{
David B. Vodušek \\ Division of Neurology, University Medical Center, Ljubljana, Slovenia
}

\section{Key Words}

Anatomy $\cdot$ Neurophysiology $\cdot$ Pelvic floor

\begin{abstract}
Neural control of pelvic organs is affected by a unique coordination of somatic and autonomic motor nervous systems. Sensory information and feedback is supplied by both visceral and somatic sensory fibers. The anatomical features of the pelvic floor and perineal muscles, and their innervation are described. Altogether more detailed information is known in humans on the peripheral innervation as compared to the central nervous system centers and connections of pelvic organ neurocontrol. Controversies in regional neuroanatomy are explained. Reports on individual variability and asymmetry - the former particularly with methods revealing structures, and the latter with functional methods - are interesting but need further validation.
\end{abstract}

Copyright (C) 2004 S. Karger AG, Basel

\section{Introduction}

Neural control of pelvic organs is affected by a unique coordination of somatic and autonomic motor nervous systems; sensory information and feedback is - as well supplied by both visceral and somatic sensory fiber systems. Some modulatory interaction between the sensory and motor systems may be achieved in the periphery, reflex integration is regulated at the spinal cord (and brainstem) level. The inputs from several higher centers are decisive for complex reflex and voluntary control, and for socially adapted behavior.

The following is an attempt at a somewhat simplified presentation of basic 'peripheral' neuroanatomical facts, along with highlighting some of the existing controversies, focusing on the somatic nervous system, the external anal sphincter and levator ani muscles.

\section{Somatic Motor Pathways}

Primary motor cortex has a connection to pelvic floor muscles nuclei in sacral spinal cord. Medial hypothalamus has connections to the Onuf's nucleus.

The motor neurons innervating the rhabdosphincters and the pelvic floor muscles originate from the Onuf nucleus in the S2-S4 anterior horn of the spinal cord. (The sacral segments constitute the lowermost part of the spinal cord, called the conus.) Within the Onuf nucleus there is some spatial separation between motor neurons concerned with the control of the urethral and of the anal rhabdosphincter. Sphincter motor neurons are uniform in size and smaller than the other alpha motor neurons. They are distinguished also by bundles of dendrites from multiple neurons projecting along transverse and longitudinal axes. The neurons demonstrate high concentrations

\begin{tabular}{ll}
\hline KARGER & ( 2004 S. Karger AG, Basel \\
0012-2823/04/0692-0087\$21.00/0 \\
Fax +4161306 12 34 & \\
$\begin{array}{l}\text { E-Mail karger@karger.ch } \\
\text { www.karger.com }\end{array}$ & $\begin{array}{l}\text { Accessible online at: } \\
\text { www.karger.com/dig }\end{array}$
\end{tabular}

Prof. David B. Vodušek, MD, PhD

Division of Neurology

University Medical Center

Ljubljana, 1525 (Slovenia)

Tel. +386152215 10, Fax +3861522 22 93, E-Mail david.vodusek@kclj.si 


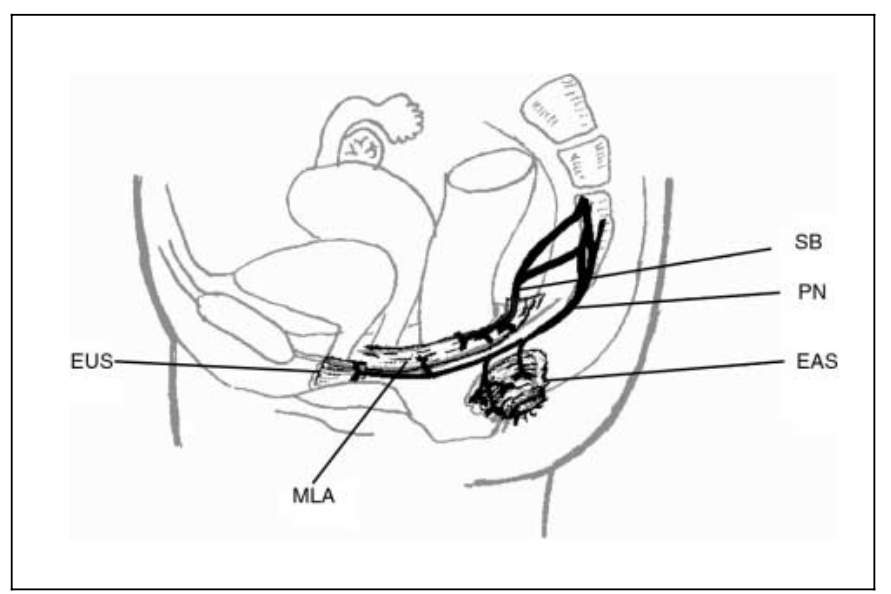

Fig. 1. The pudendal nerve $(\mathrm{PN})$ is derived from ventral rami of roots (S1),S2, S3, (S4). It continues through the greater sciatic foramen and enters in a lateral direction into the ischiorectal fossa. Its muscular branches innervate the external anal sphincter (EAS) and the external urethral sphincter (EUS). There are also muscular branches for the musculus levator ani (MLA), which is also innervated by direct branches (SB) from the sacral plexus ('from above') [modified from ref. 23].

of amino acid-, neuropeptide-, norepinephrine-, serotonin- and dopamine-containing terminals which represent the substrate for the distinctive neuropharmacologic responses of these neurons (for example, selective inhibition by kappa opioid receptor agonists) [1].

The somatic motor fibers leave the spinal cord as the ventral radiculi forming the ventral radices, fuse with the dorsal radices to constitute the spinal nerve. (The sacral roots travel within the spinal canal from levels $\mathrm{T} 12 / \mathrm{Ll}$ as the cauda equina.) After passing through to the intravertebral foramen, the nerve divides into a dorsal ramus and a ventral ramus [2].

Whereas the autonomic (parasympathetic) fibers constitute the pelvic plexus, the somatic fibers from the ventral rami (also called the sacral plexus) form the pudendal nerve. Some somatic fibers from S2-S4 probably also accompany pelvic (parasympathetic) nerves, but it is as yet unclear if this is always the case. The study from Borirakchanyavat et al. [3] convincingly demonstrated an intrapelvic somatic pathway from roots $\mathrm{S} 2,3,4$ to both levator ani and the urethral sphincter in 5 females. There is some controversy regarding the derivation and contributions of the pudendal nerve. Traditionally, the pudendal nerve is described as being derived from the S2-S4 ventral rami. A modern neuroanatomical study reports some contribution from the $\mathrm{S} 1$, and no contribution from the S4 [4]. All the branches form one major trunk - the pudendal nerve, which continues through the greater sciatic foramen and enters in a lateral direction through the lesser sciatic foramen into the ischiorectal fossa (the Alcock's canal). Some authors describe a branch at the level superior to the passage of the pudendal nerve through the greater sciatic (infrapiriformic) foramen [5] which contains fibers to the levator ani (fig. 1) and the urethral rhabdosphincter. Other authors have not found this branching [4].

It is still controversial which branches contribute to the pudendal nerve, and whether the urethral rhabdosphincter is innervated by the pelvic plexus [6] or the pudendal nerve $[5,7]$. As already said the pudendal nerve leaves the pelvis via the great sciatic foramen between the piriformis and the coccyx to enter the gluteal region. It crosses the sacrospinous ligament close to the attachment to the ischial spine sited medial to the internal pudendal vessels. It accompanies the internal pudendal artery to the lesser sciatic foramen into the pudendal canal on the lateral wall of the ischiorectal fossa. In the posterior part of the canal it gives off the inferior rectal nerve; then it branches into the perineal nerve, and the dorsal nerve of the penis/clitoris (fig. 1). (The inferior rectal nerve sometimes arises directly from the sacral plexus.) The perineal nerve is the inferior and larger terminal pudendal branch and divides into the posterior scrotal/labial and muscular branches. One of its muscular branches is 'recurrent' and innervates the anterior part of EAS. How much variability and asymmetry there is in this EAS innervation has not been explored. There are also muscular nerve branches for the levator ani. The dorsal nerve of the penis/clitoris runs forwards along the ischial ramus and the margin of the inferior pubic ramus deep to the inferior fascia of the urogenital diaphragm [2].

Normal variability of human neuroanatomy is often mentioned; there may also be some sex differences. Little is, however, known about asymmetries of anatomy; interestingly, anatomical studies apparently dissect specimens only unilaterally, so intersubject variability is noticed, but intrasubject variability (asymmetry) not [4].

\section{Levator Ani}

There are few data on the development of the external anal sphincter and the levator ani. They have been described in human embryos after 8 weeks of gestation arising from two distinct primordia [8]. Comparative anatomical studies have suggested that there is a sphincter group of muscles and a lateral 'compressor group.' 
The pelvic floor is principally made up of a pair of compound muscular sheets composed of predominantly striated muscle and usually referred to as the levator ani. There is an aperture in the midline where viscera pass through the pelvic floor. Originally the levator ani was described as consisting of the pubococcygeus, iliococcygeus and ischiococcygeus. Nowadays it is more conventional to divide the muscle into four parts: iliococcygeus, pubococcygeus, puborectalis, and ischiococcygeus (the latter being more a rudimentary muscle in man, representing little more than the sacrospinous ligament). $\mathrm{Pu}-$ borectalis arises from the lower part of the back of the symphisis pubis and forms a loop around the recto-anal flexure. Its muscle fibers are closely associated with the deep part of the external anal sphincter. Puborectalis has no posterior attachment to the vertebral column. Pubococcygeus arises from the pubis and anterior part of the obturator fasciae in continuity with puborectalis. Its fibers are directed almost horizontally backwards and lie superior to the innermost fibers of the iliococcygeus. The main body of its fibers attach to a flattened tendon which inserts behind the rectum on the ventral surface of the coccyx. The iliococcygeus is a thin muscle with its origin from the medial surface of the ischial spine. It partially overlaps the pubococcygeus to insert below it on the lateral surfaces of the terminal portion of the coccyx and the anococcygeal raphe. The ischiococcygeus (coccygeus) arises from the tip and the posterior surface of the ischial spine and inserts into the lateral surface of the lower part of the sacrum and the upper coccyx. It usually consists of just a few fibers lying on the surface of the sacrospinous ligament [8].

Morphometric measurements of the levator ani muscles by magnetic resonance imaging revealed considerable variation both in size and configuration [9].

\section{External Anal Sphincter}

External anal sphincter is usually described as a circular muscle (cf. fig. 1), the left and right halves normally functioning together. There is clinical evidence that the two halves of the muscle are innervated independently, as there is clear unilateral denervation activity after unilateral pudendal nerve lesions; also the anal reflex may be absent unilaterally. In an electrophysiological study [10], it was shown that the external anal sphincter muscle was innervated only by the pudendal nerves and that this innervation seems to be strongly lateralized. An experimental study in Rhesus monkeys has demonstrated bilat- eral denervation changes and bilateral reinnervation signs after unilateral pudendal neurectomy [11] which was attributed to interdigitation of muscle fascicles across the midline of the circular muscle.

Asymmetrical amplitudes of EAS responses on pudendal nerve stimulation were reported, implying asymmetry of pudendal innervation of muscle. 'Dominant' pudendal nerve stimulation was furthermore reported to be more facilitatory for eliciting cortical MEP of EAS [12].

Muscle fibers in the anal sphincter have been described as predominantly type one (fatigue resistant) accounting for between 65 in $99 \%$ of the fiber population. The diameters of both fiber types are small and range from 21 to $34 \mu \mathrm{m}[13]$.

The external anal sphincter has been traditionally conceptualized as a predominantly circular muscle divided into three parts. The musculus subcutaneous is a multifascicular ring of striated muscle without attachment; the superficial part an elliptical muscle attached to the coccyx, and the deep part is blending into the puborectalis [8]. As opposed to this classical description of the anal sphincter (with the concept of predominantly circumferential muscle fibers) some recent studies have stressed the 'loop concept' of the sphincter structure. The original author of the concept commented on the great degree of variation between specimens [14]. Differences in sex and age were also described. A recent review of this "new anatomy' by Bogduk [15] describes the external anal sphincter as made up of a series of three loops (fig. 2). The upper loop is made up of the puborectalis and the deep part of the external sphincter (it is attached to the pubis); the middle loop is made up of the midportion of the sphincter (it is attached posteriorly to the coccyx; anteriorly the fibers decussate in the perineal body and can be traced into the bulbospongiosus and the deep transverse perinei muscle). The basal loop contains circumferential fibers and is thought to attach to the skin anterior to the anus.

Electromyographically, only a subcutaneous and a deep part of EAS can be distinguished. Physiological differences have been described between the superficial and the deep part of the sphincter, the subcutaneous part demonstrating more tonic firing of motor units and more brisk anal reflex responses as opposed to the deep part. The subcutaneous part is reached by the needle electrode immediately after penetrating the epithelium about $1 \mathrm{~cm}$ from the anal aperture; the deeper part is reached at a depth of about $3 \mathrm{~cm}$ [16]. At a depth just above $5 \mathrm{~cm}$, the puborectalis is usually reached by the concentric needle electrode [17].

Digestion 2004;69:87-92

Neurocontrol of the Pelvic Floor 


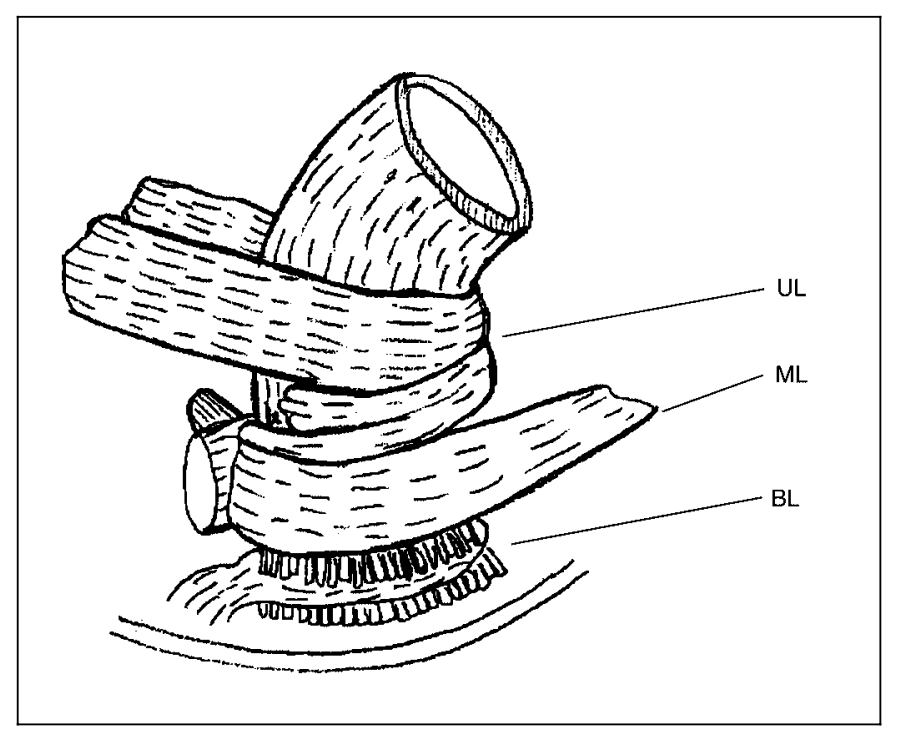

Fig. 2. The new conceptualization of the external anal sphincter - it is composed of three loops: the basal loop (BL), middle loop (ML) and upper loop (UL). The basal loop contains circumferential fibers and is attached to the skin anterior to the anus; the middle loop (the midportion of the sphincter) is attached posteriorly to the coccyx (anteriorly the muscle fibers decussate and are traced into more anterior perineal muscles); the upper loop is the deep portion of the sphincter continuing into the puborectalis [modified from ref. 15].

\section{Autonomic Innervation}

The rectum and anal canal are innervated both by a sympathetic (from the 11th or 12th thoracic and the 1st and 2 nd lumbar segments) and parasympathetic (from the vagus and 1 st, 2 nd and 3 rd sacral segments) components of the autonomic nervous system. Sympathetic nerves have an inhibitory effect on colon peristalsis and secretions. The parasympathetic stimulation increases peristalsis and secretions. Sympathetic fibers form the hypogastric plexuses. Parasympathetic supply of the left colon, rectum and anus comes from the $2 \mathrm{nd}$, $3 \mathrm{rd}$, and 4 th sacral nerves (the pelvic splanchnic nerves). Its fibers pass through the two inferior hypogastric plexuses.

\section{Afferent Pathways}

The afferent pathways from the anogenital region and pelvic region are commonly divided into the somatic and visceral. The visceral afferents accompany both parasympathetic and sympathetic efferent fibers, the somatic accompany the pudendal nerves and direct somatic branches of the sacral plexus. The different groups of afferent fibers have different reflex connections, and may transmit at least to some extent different afferent information. In principle, however, all afferent neurons have their cell bodies in spinal ganglia; those accompanying somatic and parasympathetic pathways in the sacral segments (S1/S2-S4) those accompanying sympathetic fibers in Th11-L2 dorsal root ganglia. The sensory neurons are bipolar and send long processes to the periphery and the central process into the dorsal column of the spinal cord, or to the brainstem [2].

Afferent pathways accompanying sympathetic nerves encompass sensory neurons residing in the T11-L2 dorsal root ganglia and terminating in the dorsal horn (lamina I V) of the spinal cord. High threshold sympathetic afferents transmit nociceptive (pain) information [18].

Afferent pathways accompanying somatic motor pathways include several groups of sensory fibers. Somatic afferents from the external urethral sphincter mechanism, distal vaginal mucosa and the anogenital region travel in the pudendal nerves, have cell bodies in $\mathrm{S} 1 / \mathrm{S} 2-\mathrm{S} 3 / \mathrm{S} 4$ dorsal root ganglia, and terminate in the sacral segments of the spinal cord in regions that overlap with those of afferents accompanying parasympathetic fibers in the pelvic nerve from the bladder [18].

Our own studies with selective direct intraoperative recordings made from the dorsal sacral roots (on electrical stimulation of the dorsal clitoral and penile nerves) have demonstrated that in most patients pudendal afferent activity is present in the $\mathrm{S} 2$ and $\mathrm{S} 3$ roots bilaterally, but in some patients a small contribution can also be demonstrated in the S1 roots. Variability and asymmetry of afferents was demonstrated in a group of 105 subjects without peripheral nervous system involvement. Our measurements demonstrated that penile/clitoral afferents contributed mostly to $\mathrm{S} 2$ roots $(60.5 \%)$, then to $\mathrm{S} 3$ roots $(35.5 \%)$ and gave occasionally some contribution to S1 roots $(4 \%)$. S4 roots were mapped only in few subjects but a contribution from the dorsal penile/clitoral nerve was never obtained. The significant finding was asymmetry of responses in $56 \%$ of subjects. Pudendal afferent distribution was confined to a single level in $18 \%$ and even to a single root in $7.6 \%$ of patients (fig. 3) [19, 20]. Similar findings were also obtained by mapping anal mucosal afferents in sacral roots $\mathrm{S} 1$ to $\mathrm{S} 3$ in 24 patients who underwent selective lumbosacral dorsal rhizotomy for relief of spasticity. Anal afferents contributed to $\mathrm{S} 2$ and $\mathrm{S} 3$ roots as main carriers and exceptionally to S1 root. Again the distribution was often asymmetrical, and in $11 \%$ the primary and only carrier of anal afferents was a single root [21]. 


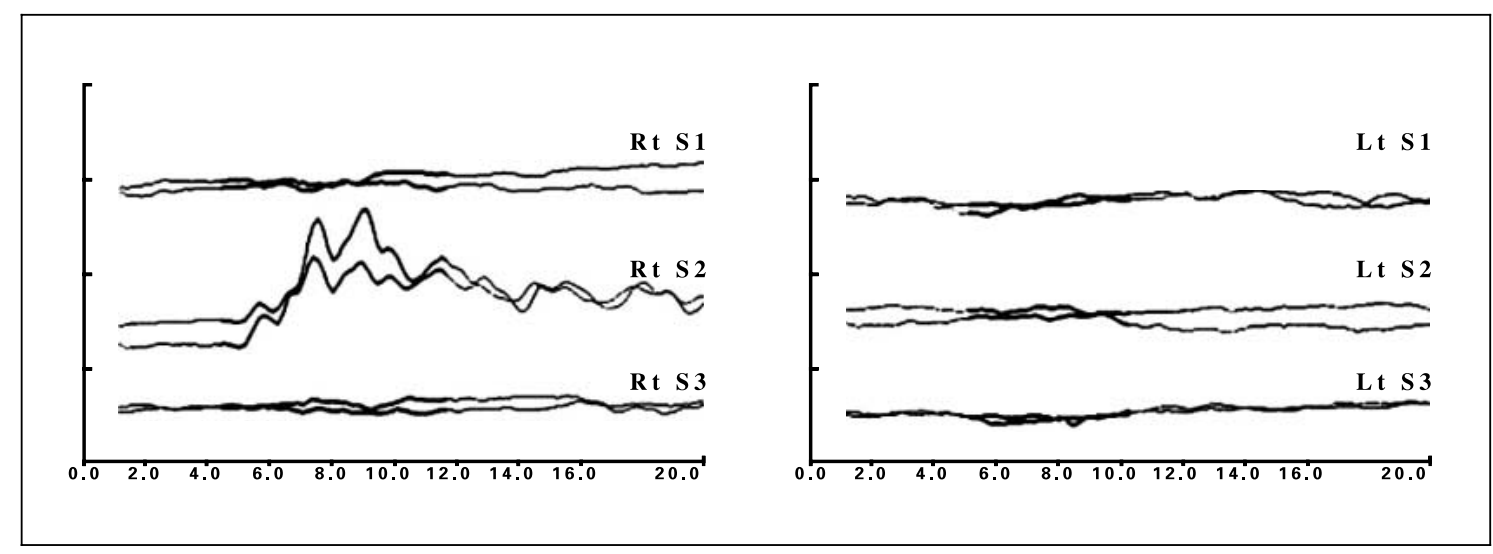

Fig. 3. Spinal nerve root action potentials recorded from right (Rt) and left $(\mathrm{Lt})$ dorsal roots $\mathrm{S} 1-\mathrm{S} 3$ on penile electrical stimulation in a 4-year-old boy. The recordings are performed intraoperatively with hook electrodes. An extremely asymmetrical distribution of afferent activity from the penis is demonstrated (all activity is limited to the right S2 root). Two averages of 100 responses for each group are superimposed. The vertical scale is $50 \mu \mathrm{V}$ per division, the horizontal scale is in ms.

Electrophysiological recordings of somatosensory evoked potentials have demonstrated differences of afferent innervation of the distal and proximal urethra suggesting that the sensory innervation of the proximal urethra is provided by pelvic nerve afferents and the distal urethra by pudendal nerve afferents [22]. The distribution of cerebral SEP on pudendal nerve stimulation shows largest amplitude potentials over the central $(\mathrm{Cz})$ area corresponding to the Penfield's sensory homunculus (i.e. representing the anogenital region on the medial surface of the postcentral gyrus in the primary somatosensory cortex) [22].

There is some controversy regarding the proprioceptive afferent input from perineal and pelvic floor muscles. Several studies have failed to demonstrate muscle spindles in the urethral rhabdosphincter, therefore thick myelinated efferent fibers from that muscle should be lacking; but such afferents are certainly coming from other pelvic floor musculature (particularly the levator ani) where muscle spindles are present. Definitely the pudendal nerve contains large and small diameter afferents (and also myelinated and unmyelinated efferent axons. Some of the small myelinated efferent axons may be gamma motor neurons innervating spindle intrafusal fibers) [18].

The spinal pathways which transmit sensory informations from the visceral afferent terminations in the spinal cord to more rostral structures can be found in the dorsal, lateral, and ventral spinal cord columns. The dorsal column projection consists of primary afferent collaterals which run ipsilaterally to synapse in the gracillis (dorsal column) nuclei. This pathway transmits information about the sensation of innocuous sensations from the pelvic floor muscles. The lateral columns also transmit information concerning pain sensations from perineal skin, as well as sexual sensations. In humans this pathway is situated superficially just ventral to the equator of the cord and is probably the spinothalamic tract [18].

\section{Conclusion}

Altogether more detailed information is known in humans on the peripheral innervation of the pelvic floor and the anogenital region as compared to the central nervous system centers and connections of pelvic organ neurocontrol. There are, however, several important controversial issues even related to peripheral innervation. At least some of the dispute is probably due to normal anatomical variability; the findings of significant asymmetry in some studies are intriguing and need confirmation - preferably by different and complementary methods of investigation. Neurophysiological techniques may be helpful in resolving some of the functional anatomical issues, particularly in the peripheral innervation. Regarding the central tracts and centers, the modern functional imaging techniques - particularly the functional magnetic resonance imaging - will probably add important new knowledge in the near future. 


\section{References}

1 Thor KB, Nickolaus S, Helke CJ: Autoradiographic localization of 5-hydroxytryptamine ${ }_{1 \mathrm{~A}}$, 5-hydroxytryptamine ${ }_{1 \mathrm{~B}}$ and 5-hydroxytryptamine $_{1 \mathrm{C} / 2}$ binding sites in the rat spinal cord. Neuroscience 1993;55:235-252.

2 Bannister LH, et al (eds): Gray's Anatomy. The Anatomical Basis of Medicine and Surgery, ed 38, New York/London, Churchill-Livingstone, 1995.

3 Borirakchanyavat S, Abosief SR, Carroll PR, Tanagho EA, Lue TF: Continence mechanism of the isolated female urethra: An anatomical study of the intrapelvic somatic nerves. J Urol 1997; 158:822-826.

4 Marani E, Pijl MEJ, Kraan MC, Lycklama à Nijeholt GAB, Videleer AC: Interconnection of the upper ventral rami of the human sacral plexus: A reappraisal for dorsal rhizotomy in neurostimulation operations. Neurourol Urodynam 1993;12:585-598.

5 Jünemann K, Lue TF, Schmidt RA, Tanagho EA: Clinical significance of sacral and pudendal nerve anatomy. J Urol 1988;139:74.

6 Gil-Vernet S: Innervation somatique et végétative des organes génito-urinaires. Acta Urol Belg 1964;32:265-293.

7 Vodušek DB, Light JK: The motor nerve supply of the external urethral sphincter muscles. Neurourol Urodynam 1983;2:193-200.
8 Cook TA, Mortensen N: Colon, rectum, anus, anal sphincters and the pelvic floor; in Pemberton JH, Swash M, Henry MM (eds): The Pelvic Floor: Its Functions and Disorders. London, Saunders, 2002, pp 61-76.

9 Tunn R, Delancey JO, Ashton-Miller JA, Quint LE: Anatomic variations in the levator ani muscle, endopelvic fascia, and urethra in nulliparas evaluated by magnetic resonance imaging. Am J Obstet Gynecol 2003;188:116121.

10 Percy JP, Neill ME, Swash M, Parks AG: Electrophysiological study of motor nerve supply of pelvic floor. Lancet 1981;i:6-17.

11 Wunderlich M, Swash M: The overlapping innervation of the two sides of the external anal sphincter by the pudendal nerves. J Neurol Sci 1993;59:97-109.

12 Hamdy S, Enck P, Aziz Q, Uengoergil S, Hobson A, Thompson DG: Laterality effects of human pudendal nerve stimulation on corticoanal pathway: Evidence for functional asymmetry. Gut 1999;45:58-63.

13 Beersiek F, Parks AG, Swash M: Pathogenesis of ano-rectal incontinence: A histometric study of the anal sphincter musculature. J Neurol Sci 1979;42:111-127.

14 Ayoub SF: Anatomy of the external anal sphincter in man. Acta Anat 1979;105:25-36.

15 Bogduk N: Issues in anatomy: The external anal sphincter revisited. Aust NZ J Surg 1996; 66:626-629.

16 Podnar S, Vodušek DB: Standardisation of anal sphincter EMG: High and low threshold motor units. Clin Neurophysiol 1999;110: 1488-1491.
17 Sato T, Konishi F, Kanazawa K: Variations in motor evoked potential latencies in the anal sphincter system with sacral magnetic stimulation. Dis Colon Rectum 2000;43:966-970.

18 Torrens M, Morrison JFB (eds): The Physiology of the Lower Urinary Tract. London, Springer, 1987.

19 Deletis V, Vodušek DB, Abbott R, Epstein F Turndorf $\mathrm{HH}$ : Intraoperative monitoring of dorsal sacral roots: Minimizing the risk of iatrogenic micturition disorders. Neurosurgery 1992;30:72-75.

20 Huang JC, Deletis V, Vodušek DB, Abbott R: Preservation of pudendal afferents in sacral rhizotomies. Neurosurgery 1997;41:411-415.

21 Kržan M, Kothbauer K, Deletis V, Enck P Abbott R: Comparison of the radicular distribution of anal and penile/clitoral afferents. Electroenceph Clin Neurophysiol 1999;110: 2383.

22 Sarica Y, Karacan I: Electrophysiological correlates of sensory innervation of the vesico-urethral junction and urethra in man. Neurourol Urodynam 1988;6:477-484.

23 Swash M: Electrophysiological investigation of the posterior pelvic floor musculature; in Pemberton JH, Swash M, Henry MM (eds): The Pelvic Floor: Its Functions and Disorders. London, Saunders, 2002, pp 213-236. 